\title{
The mapping of maximum annual energy yield azimuth and tilt angles for photovoltaic installations at all locations in South Africa
}

\author{
Tebogo Matshoge
}

Department of Electrical Engineering, University of Cape Town

Adoniya Ben Sebitosi

Centre for Renewable and Sustainable Energy Studies, University of Stellenbosch

\begin{abstract}
Photovoltaic (PV) technology is fast emerging as a viable energy supply option in mitigation against environmental degradation through the burning of traditional fossil fuels. The cost of the technology, however, still poses a major challenge, as the efficiencies are generally still quite modest. Current research efforts to improve efficiency are mainly focused on component physics and manufacturing technologies. Little attention seems to be paid to improved system design at field level. Traditionally it is assumed that a panel installed at a tilt angle that is equal to the latitude at a location should achieve maximum annual energy yield for a non-tracking installation. However, in practice, due to a number of factors such as wind speed, wind direction, air temperature, global and diffuse irradiation and other climatic factors, the optimum azimuth and tilt get more convoluted. In this paper the optimum angles (azimuth and tilt) to maximise annual energy yield for fixed angle $P V$ installations at all locations in South Africa have been tabulated. Climate data software together with solar design software were used in determining the angles. The availability of these tables will offer an additional support tool to the country in promoting the growth of $P V$ as a viable alternative energy generation technology for both urban as well as the most secluded rural areas that are not grid connected.
\end{abstract}

Keywords: photovoltaics, South Africa, tilt, azimuth

\section{Introduction}

South Africa is currently facing a range of energy related problems that include energy reliability, environmental sustainability and tariff hikes (Sebitosi et al., 2008; Sebitosi \& Pillay, 2008; Sebitosi \& Pillay 2008). The Department of Energy also identifies access for all to electricity as one of the primary goals of South Africa's energy policy. The need to integrate non-grid technologies into the Integrated National Energy Planning (INEP) as complementary supply-technologies to grid extension has been particularly highlighted (DME, 2003). Solar energy is a most readily accessible resource in South Africa and potentially offers an ample opportunity for alternative power generation that is also clean. In addition, there is a growing photovoltaic (PV) manufacturing sector in the country with annual panel-assembly capacity totalling 5MW. Despite this great potential, solar PV installations are still very expensive for ordinary users, more especially those in rural South Africa. Thus, this cost is one of the major limiting factors to the full utilization of PV technologies.

\section{Motivation}

Designing an installation to yield maximum annual energy helps to minimise the necessary installed capacity and reduce the cost of equipment. To achieve this, a generic solar collector must be mounted at right angles to the sun's rays. Ideally this is achieved by mounting the collector on a two-axis tracker that continuously tracks the sun by the hour and through the seasons. In practice, however, the method is quite cumbersome and inconvenient. Thus, the majority of installations are with fixed mountings. Figure 1 illustrates the reduction in solar intensity at location $\mathrm{B}$ that receives the sun at a smaller angle than location A.

Traditionally it is assumed that a collector that is mounted at a tilt angle that is equal to the latitude of a location, combined with an azimuth angle that is parallel to the equator, should achieve maximum annual energy collection. In the case of photovoltaics, however, the situation is more complicated.

A basic PV panel consists of several solar cells. 


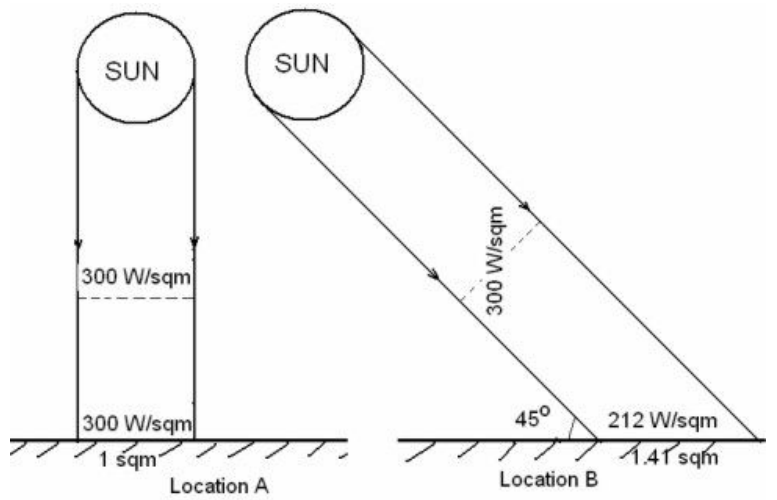

Figure 1: An illustration of the reduction of radiation intensity per square metre due to sun angle

Each solar cell can be modelled as a basic p-n junction, and hence the classic diode equation can be used in modelling outputs for the solar panel.

The diode equation is given by equation 1 .

$$
I=I_{o}\left(e^{\frac{q v}{k T}}-1\right)
$$

Where $\mathrm{T}$ is the temperature of the solar cell.

From this, various models for the electrical energy output of a PV panel have been derived. One such model is presented in (Medica et al., 1996):

$$
P_{1}=P_{0}\left(1-\gamma\left(T_{1}-T_{0}\right)\right) H / H_{0}
$$

Where:

$\mathrm{P}_{0}=$ Power at standard condition $\left(25^{\circ} \mathrm{C}\right.$ and 1000 $\mathrm{W} / \mathrm{m}^{2}$ )

$\mathrm{H}=$ Value of solar irradiance incident of the module $\left(\mathrm{W} / \mathrm{m}^{2}\right)$

$\mathrm{H}_{0}$ is reference solar radiation $=1000 \mathrm{~W} / \mathrm{m}^{2}$ (to the horizontal surface)

$\gamma=$ Power correction coefficient

$\mathrm{T}_{1}=$ Panel temperature

$\mathrm{T}_{0}=$ Standard temperature $\left(25^{\circ} \mathrm{C}\right)$

From the above, it is evident that the output power of the PV panel is directly proportional to the sun's radiation, but also inversely proportional to the sun's heat. Solar radiation is comprised of about $9 \%$ ultra-violet, $41 \%$ of visible radiation (which increases the output current) and about $50 \%$ infrared, which constitutes the heat. Therefore, in order to maximize the electrical energy yield of a PV panel, one must minimize the effect of the heat component while maximizing the effect of the light component.

Currently there is no known technology that can filter the infrared before the solar radiation can strike the PV panel. However, the presence of other climatic factors at a location can impact on the tem- perature of the panel. These factors include wind speed, wind direction, humidity and due point. Consequently it may be necessary to rotate a panel slightly away from the position where it catches maximum radiation to one where catching a bit of a cool breeze (as well) results in more electrical energy yield.

The primary aim of this paper is to provide a comprehensive database of optimum tilt and azimuth angles to support PV installation engineers at any location in South Africa, regardless of how remote it may be.

\section{Methodology}

Initially an outline of a South African map was obtained and divided into grids. The intersection points of the grid lines were considered as the coordinate locations and used as locations for study. This is illustrated in Figure 2. These coordinates were used to generate climate data for each point on the map using Meteonorm climate simulation software. The simulated data contained the following output parameters namely, month, day of the month, hour, global radiation on a horizontal plane, diffuse radiation on a horizontal plane, air temperature, wind direction and wind speed. These are important in that they influence the overall performance of the PV module and need to be specified accurately for correct system design.

The climate data files were then inputted into PV Design Pro-S software and the annual energy yield for each intersection point was calculated. The design package allows the user to vary the azimuth and tilt angles of the panels used.

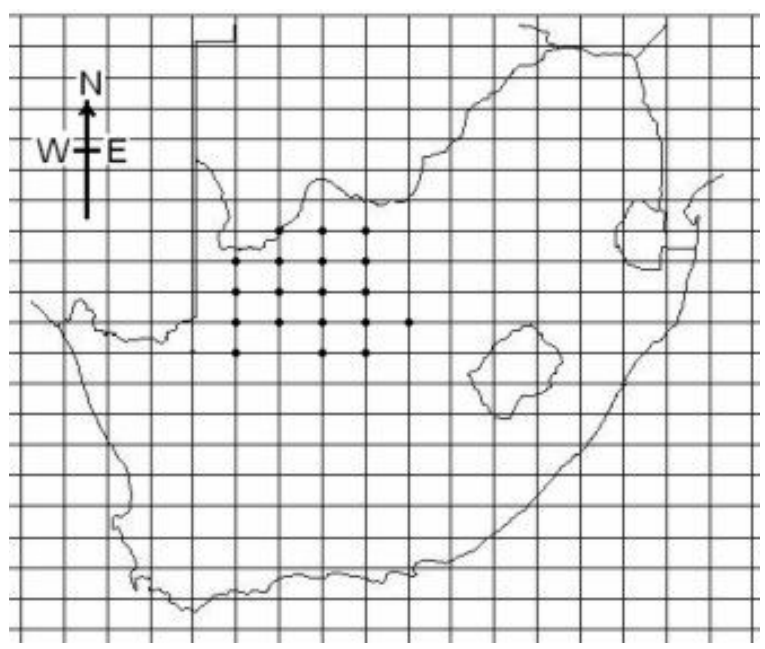

Figure 2: A South African map demarcated into grids of coordinate points

For a particular intersection point (coordinate location) the azimuth and tilt angle combination resulting in the highest annual energy yield was recorded. The rest of the parameters were kept constant. These included, the load profile, which was 
kept at an average of 18466 Wh per day for weekly load and 18000 Wh per day for the weekend load. Thus, the only parameters varied throughout the investigation were the climate (determined by the location), the tilt and azimuth angles.

\section{Simulation results}

\subsection{Azimuth angle and tilt}

Initially the assumption made was that the tilt angle could be set at latitude as suggested by Bekker (2007). Thus, to obtain the optimum azimuth angle, the tilt was kept constant at latitude and only the azimuth was varied until the maximum possible annual energy yield was obtained. This was repeated for all the points indicated in the map shown in Figure 2.

Once the optimum azimuth angles were obtained, the process was repeated to find the optimum tilt angles. Using the optimum azimuth angles obtained earlier, tilt angles were varied to obtain new values that yielded the maximum annual energy.

Tables 1 and 2 give the results of the optimum azimuth and tilt angles respectively, for all point locations investigated in this project. Table 1 shows a general trend of the azimuth angle increasing from west to east. This trend also holds in the case of the tilt angles as depicted in Table 2.

\subsection{A guide to using the optimum yield angle tables}

In practice a given location is unlikely to be at the coordinates indicated in the tables but somewhere in between. To address that problem, a method to obtain the required azimuth and tilt angles for any location is illustrated in this section.

In South Africa the average distance between any given adjacent longitude, ranges between approximately $90 \mathrm{~km}$ and $111 \mathrm{~km}$. The distance between latitude degrees remains constant at roughly $111 \mathrm{~km}$. In addition, the results obtained from both Meteonorm and PV Design Pro-S are valid for a distance of approximately $40 \mathrm{~km}$ from the location where the results are obtained.

To obtain the coordinates of any location it is recommended that a GPS (global positioning system) be employed.

Linear Interpolation is a method of constructing new data points within the range of a discrete set of known points.

Table 1: Optimum Azimuth in degrees at coordinate points in South Africa

\begin{tabular}{|c|c|c|c|c|c|c|c|c|c|c|c|c|c|c|c|c|c|c|}
\hline \multicolumn{19}{|c|}{ Longitude } \\
\hline Coordinate 16 & 17 & 18 & 19 & 20 & 21 & 22 & 23 & 24 & 25 & 26 & 27 & 28 & 29 & 30 & 31 & 32 & 33 & 34 \\
\hline \multicolumn{19}{|l|}{ Latitude } \\
\hline 23 & & & & & & & & & & & 45.2 & 51 & 53.1 & 53 & 49.5 & 56 & & \\
\hline 24 & & & & & & & & & & 42.3 & 50.6 & 45.2 & 46 & 49.2 & 50 & 55 & & \\
\hline 25 & & & & 33 & 32.8 & 32.1 & 37 & 41.8 & 41 & 42 & 44.4 & 49.9 & 47.1 & 49.1 & 53 & 53 & & \\
\hline 26 & & & & 34.3 & 38.7 & 35 & 41 & 38.5 & 42.8 & 43 & 45.1 & 48 & 50 & 46.9 & 53 & 49.7 & & \\
\hline 27 & & & & 33.6 & 35.9 & 38.6 & 40 & 41.1 & 44 & 45 & 47 & 49 & 53 & 51.8 & 52.3 & 57.6 & 55 & \\
\hline 26.3 & 28 & 28.2 & 28.6 & 32 & 32 & 41 & 36.7 & 38 & 45 & 46 & 44 & 42.2 & 50 & 49 & 52.8 & 57 & 55.3 & \\
\hline 28.9 & 29 & 27.4 & 29.7 & 37.8 & 37 & 43.1 & 41 & 40 & 42 & 41.4 & 43 & 47 & 48.4 & 44.5 & 51 & 53 & 56 & \\
\hline 30 & 26.7 & 33.9 & 31.6 & 34.2 & 35.4 & 35.8 & 37.0 & 41.2 & 41.9 & 44 & 50.4 & 47.7 & 50.3 & 45.5 & 55.1 & 56.5 & & \\
\hline 31 & 29.7 & 30.7 & 36.4 & 31.5 & 36.7 & 34.3 & 36.1 & 38.3 & 42.2 & 43.9 & 43.6 & 49 & 47.3 & 50.1 & & & & \\
\hline 32 & & 35.7 & 34 & 30,8 & 34 & 40.9 & 39.1 & 40.7 & 42.1 & 43.2 & 45.2 & 45.7 & 48 & 50.1 & & & & \\
\hline 33 & & 40.1 & 37.7 & 38.8 & 41 & 47.1 & 44 & 47 & 48.6 & & & & & & & & & \\
\hline 34 & & 38.2 & 38.9 & 42.8 & 40.3 & 41.8 & 41 & 45.1 & 44.9 & 48.2 & & & & & & & & \\
\hline 35 & & & 38.2 & & & & & 46.3 & & & & & & & & & & \\
\hline
\end{tabular}

Table 2: Optimum tilt angles in degrees at coordinate points in South Africa

\begin{tabular}{|c|c|c|c|c|c|c|c|c|c|c|c|c|c|c|c|c|c|c|}
\hline \multicolumn{19}{|c|}{ Longitude } \\
\hline Coordinate 16 & 17 & 18 & 19 & 20 & 21 & 22 & 23 & 24 & 25 & 26 & 27 & 28 & 29 & 30 & 31 & 32 & 33 & 34 \\
\hline \multicolumn{19}{|l|}{ Latitude } \\
\hline 23 & & & & & & & & & & & 258 & 256 & 257 & 265 & 262 & 265 & & \\
\hline 24 & & & & & & & & & & 252 & 255 & 259 & 267 & 263 & 263 & 264 & & \\
\hline 25 & & & & 229 & 244 & 242 & 241 & 246 & 252 & 255 & 252 & 256 & 259 & 254 & 261 & 261 & & \\
\hline 26 & & & & 231 & 232 & 235 & 255 & 251 & 243 & 255 & 260 & 254 & 256 & 256 & 256 & 266 & & \\
\hline 27 & & & & 236 & 240 & 246 & 239 & 249 & 250 & 249 & 255 & 259 & 250 & 254 & 253 & 259 & 259 & \\
\hline 230 & 232 & 216 & 220 & 226 & 233 & 228 & 251 & 250 & 246 & 250 & 251 & 256 & 255 & 259 & 259 & 259 & 267 & \\
\hline 238 & 221 & 218 & 225 & 235 & 233 & 237 & 242 & 247 & 241 & 253 & 255 & 248 & 254 & 257 & 261 & 259 & 269 & \\
\hline 30 & 217 & 227 & 235 & 234 & 225 & 232 & 251 & 243 & 248 & 251 & 243 & 256 & 258 & 259 & 263 & 261 & & \\
\hline 31 & 226 & 233 & 229 & 215 & 225 & 221 & 231 & 242 & 242 & 244 & 247 & 257 & 257 & 263 & & & & \\
\hline 32 & & 232 & 217 & 230 & 218 & 223 & 235 & 245 & 235 & 243 & 242 & 257 & 262 & 265 & & & & \\
\hline 33 & & 234 & 225 & 221 & 240 & 239 & 242 & 248 & 256 & 249 & 257 & 258 & & & & & & \\
\hline 34 & & 232 & 229 & 235 & 239 & 245 & 251 & 249 & 250 & 252 & & & & & & & & \\
\hline 35 & & & 227 & & & & & & 250 & & & & & & & & & \\
\hline
\end{tabular}




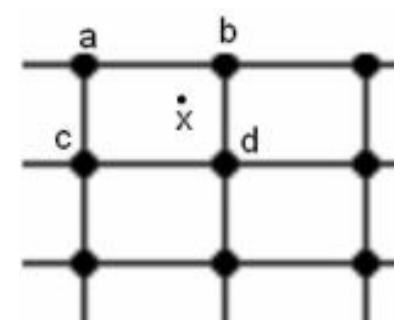

Figure 3: Coordinates $a, b, c$ and $d$ are given in the table but $x$ is not

Figure 3 illustrates a location, $\mathrm{x}$, that is not listed in the azimuth and tilt tables. The explanation below will illustrate how to obtain the required angles for $\mathrm{x}$.

The first step is to interpolate the angles at two new points, $r$ and $s$ as illustrated in Figure 4.

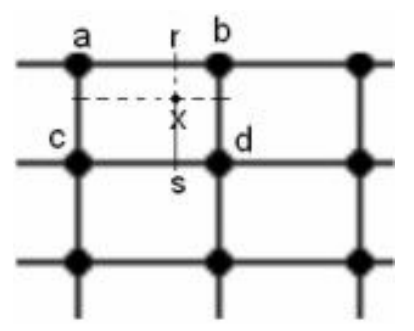

Figure 4: Illustration of the interpolation

Given the two known data points (a) and (b) in Figure 4, the required angle at $r$ can be found as follows. Note that the closer $r$ is to $b$ the closer the values of their angles will be.

Let the angle at $\mathrm{a}$ be $\mathrm{m}$ and $\mathrm{at} \mathrm{b}$ be $\mathrm{n}$. (Assume that $m$ is bigger than $n$ ).

Linear interpolation assumes that the values of the points from $a$ to $b$ decrease linearly from $m$ to $\mathrm{n}$. Then the total decrease between $\mathrm{a}$ and $\mathrm{b}$ is $(\mathrm{m}-\mathrm{n})$ units.

The decrease at $r=[(m-n) a r / a b]$

Where,

ar is the distance between points $a$ and $r$ $\mathrm{ab}$ is the distance between points $\mathrm{a}$ and $\mathrm{b}$
Therefore the value at $\mathrm{r}=\mathrm{m}-[(\mathrm{m}-\mathrm{n}) \mathrm{ar} / \mathrm{ab}]$

Next (using the method above) one finds the value at s using the angles at $\mathrm{c}$ and $\mathrm{d}$.

Finally, using the values obtained at $r$ and $s$, one interpolates the value at $\mathrm{x}$.

\subsection{Verification of the Interpolation Method}

Table 4 compares annual energy yield obtained from the interpolated yield angles with that of the simulated yield angles. Eight sample locations were considered. Also included, is the error between the two, calculated and simulated energy yield results.

From Table 3 it is clear that the percentage error in annual energy yield between the results obtained from the interpolated yield angles and simulated yield angles is small, thus negligible. Hence the interpolation method is accurate.

\section{Concluding remarks}

The cost of PV technology remains high in South Africa and it is important to optimise system design and performance to minimise installation costs. Due to a number of climatic and location related parameters, traditional installations that are fixed at tilt angles dependent on latitude alone do not attain optimum annual energy yields.

In this paper the tables of optimum azimuth and tilt angles for locations in South Africa have been successfully produced. GPS tools are now readily available to consumers and can be used to determine the coordinates of any given location. In addition, the linear interpolation method for calculating the optimum yield angles at any location has been demonstrated and validated through simulation.

\section{References}

Bekker B., (2007). Irradiation and PV array energy output, cost and optimal positioning estimation of South Africa. Journal of Energy in Southern Africa, Vol. 18 No. 2 May 2007.

Table 3: Comparison between calculated and simulated annual energy yield for sample points not on the map

\begin{tabular}{cccc}
\hline Location & $\begin{array}{c}\text { Interpolated annual } \\
\text { energy yield }\end{array}$ & $\begin{array}{c}\text { Simulated annual } \\
\text { energy yield }\end{array}$ & Error (\%) \\
\hline $\mathrm{X} 1\left(27^{\circ} \mathrm{S}-24.5^{\circ} \mathrm{E}\right)$ & 56.883 & 56.909 & 0.046 \\
\hline $\mathrm{X} 2\left(27^{\circ} \mathrm{S}-25.5^{\circ} \mathrm{E}\right)$ & 55.701 & 55.608 & -0.166 \\
\hline $\mathrm{X} 3\left(27^{\circ} \mathrm{S}-26.5^{\circ} \mathrm{E}\right)$ & 52.892 & 55.948 & 0.106 \\
\hline $\mathrm{X} 4\left(27^{\circ} \mathrm{S}-27.5^{\circ} \mathrm{E}\right)$ & 53.835 & 53.870 & 0.065 \\
\hline $\mathrm{Y} 1\left(27.5^{\circ} \mathrm{S}-24^{\circ} \mathrm{E}\right)$ & 56.574 & 56.565 & -0.016 \\
\hline $\mathrm{Y} 2\left(28.5^{\circ} \mathrm{S}-24^{\circ} \mathrm{E}\right)$ & 58.066 & 58.145 & 0.136 \\
\hline $\mathrm{Y} 3\left(29.5^{\circ} \mathrm{S}-24^{\circ} \mathrm{E}\right)$ & 56.490 & 56.459 & -0.055 \\
\hline $\mathrm{Y} 4\left(30.5^{\circ} \mathrm{S}-24^{\circ} \mathrm{E}\right)$ & 55.907 & 55.968 & 0.109 \\
\hline
\end{tabular}


DME (2003). White Paper on Renewable Energy, Department of Minerals and Energy Republic of South Africa, November 2003, Part 5. www.dme.gov.za/energy/renewable.stm.

Medica M., Jurin G., and Frankovic B., (1996). The analysis of PV power supply availability using the reference year data - Faculty of Engineering, University of Rijeka, 51000 Rijeka, Vukovarska 58, Croatia.

Sebitosi A. B., (2008). Energy Efficiency, Security of Supply and the Environment in South Africa: Moving Beyond the Strategy Documents. Energy, Volume 33, Issue 11, November 2008, Pages 1591-1596.

Sebitosi, A. B., and Pillay P., (2008). Renewable energy and the environment in South Africa: A way forward. Energy Policy, Volume 36, Issue 9, September 2008, Pages 3312-3316.

Sebitosi A. B., and Pillay P., (2008). Grappling with a half-hearted policy: The case of renewable energy and the environment in South Africa. Elsevier Energy Policy Volume 36, Issue 7, July 2008, Pages 2513-2516.

Received 12 December 2009; revised 11 June 2010 